\title{
Novel methodology for the synthesis of $\alpha$-indolyl-glycine containing peptide via direct asymmetric Friedel-Crafts reaction to peptidyl imine
}

Tsubasa Inokuma, Kodai Nishida, Akira Shigenaga, Ken-Ichi Yamada, Akira Otaka

Tokushima University, Japan

https://doi.org/10.17952/35EPS.2018.016

Peptides which contain unnatural amino acids are attractive novel drug candidates due to their biological activity superior to those of the peptides consisting of only proteinogenic amino acids. [1] These peptides are conventionally prepared by two steps; (1) asymmetric synthesis of unnatural amino acid unit, and (2) installation of the unit by Fmoc or Boc Solid-phase peptide synthesis (Fig. 1-A). However, the present procedure requires multi-step of reaction, including removal of the protective groups of amino and carboxy groups and protection of the amine moiety by Fmoc group, to prepare diverse of peptide. To develop new methodology which addresses this problem, we envisioned an asymmetric construction of unnatural amino acid units in a growing peptide chain (Fig. 1-B). [3] If direct asymmetric 1,2-addition of $\alpha$-iminopeptideis realized, changing of the nucleophiles enables easy access to a diverse range of unnatural amino acid-containing peptides.

(A) conventional method

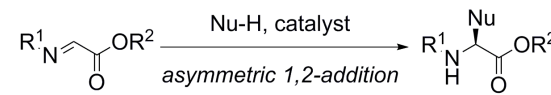

(B) This study

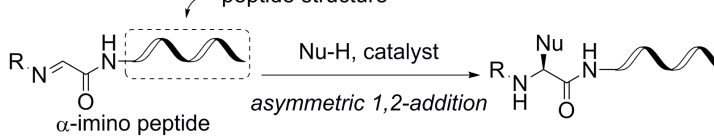

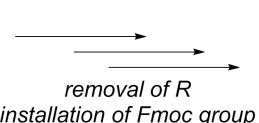
installation of Fmoc group
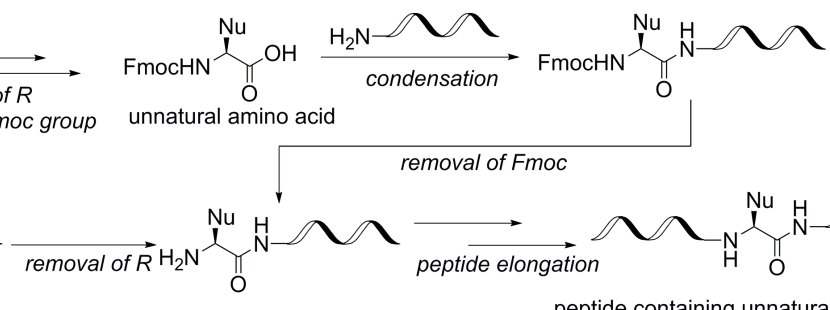

removal of Fmoc

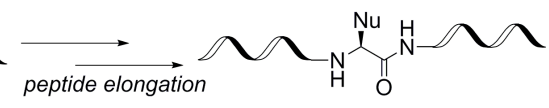

peptide containing unnatural amino acids

Figure 1: Procedures of the synthesis of peptides which contain unnatural amino acids.

We planned to use a hydrophobic anchor that makes the peptidic substrate soluble in less-polar organic solvents [2] because peptides are hardly soluble in less-polar organic solvents which are often most suitable for catalytic asymmetric reactions. As an unnaturalunit of the target peptide, $\alpha$-indolyl glycine is chosen because this unit is a promising analog to phenylalanine, tyrosine or tryptophan. An asymmetric construction of this unit was accomplished via a Friedel-Crafts reaction of N-2-nitrophenylsulfenyl (Nps)-protected $\alpha$-imino ester and indole. [4] In this study, we planned to incorporate this reaction into our synthetic concept to synthesize an $\alpha$-indolyl glycine-containing peptide. The outline of this study is shown in Fig. 2. At first, peptide elongation is performed on the amine moiety of a hydrophobic anchor using liquid-phase peptide synthesis (step 1). Next, condensation of N-Nps glycine on the growing peptide chain followed by oxidation of the N-terminal residue provides requisite imino peptide (step 2). Then, asymmetric Friedel-Crafts reaction of indole on the resulting imine is performed (step 3). Subsequent removal of the Nps group followed by usual manipulations for peptide elongation, cleavage of anchor, and global deprotection by acidic treatment would afford the desired peptides containing $\alpha$-indolyl glycine (step 4).

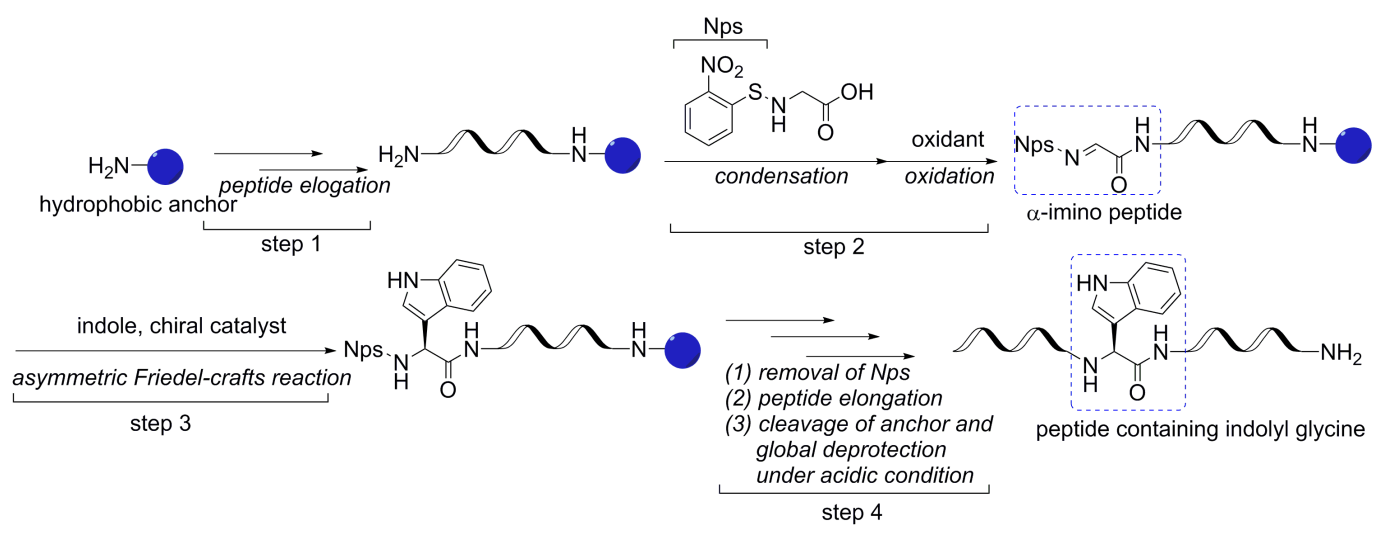

Figure 2: Outline of this study: Synthesis of a peptide bearing $\alpha$-indolyl glycine. 
We used bis(4-docosyloxyphenyl) methyl (Dpm (C22)) amine 1 which was reported by Takahashi as the hydrophobic anchor of our synthesis (Fig. 3). [2a] First, three glycine residues were installed into anchor 1 and the N-terminal amino group was protected by an Nps group. Next, MnO2-mediated oxidation of 2 was performed under our previously established conditions to give $\alpha$-imino peptide 3. [5] In the presence of BINOL-derived chiral phosphoric acid 4 [6], an asymmetric Friedel-Crafts reaction of 3 and indole successfully produced $\alpha$-indolyl glycine-containing adduct 5. Indole of this adduct 5 was then protected by an Alloc group by Alloc-imidazole [7]. After that 2-mercaptopyridine-mediated removal of the Nps group, condensation of Fmoc-Tyr $(\mathrm{Ot}-\mathrm{Bu})-\mathrm{OH}$, and removal of Fmoc group by treatment of piperidine afforded the protected tetrapeptide 6. Two-step deprotection involving acidic treatment and Pd-mediated removal of the Alloc group afforded unprotected tetrapeptide 7. Although the chemical yield and stereoselectivity of this process remain to be improved, we demonstrated the first example of direct asymmetric reaction to imino peptide.

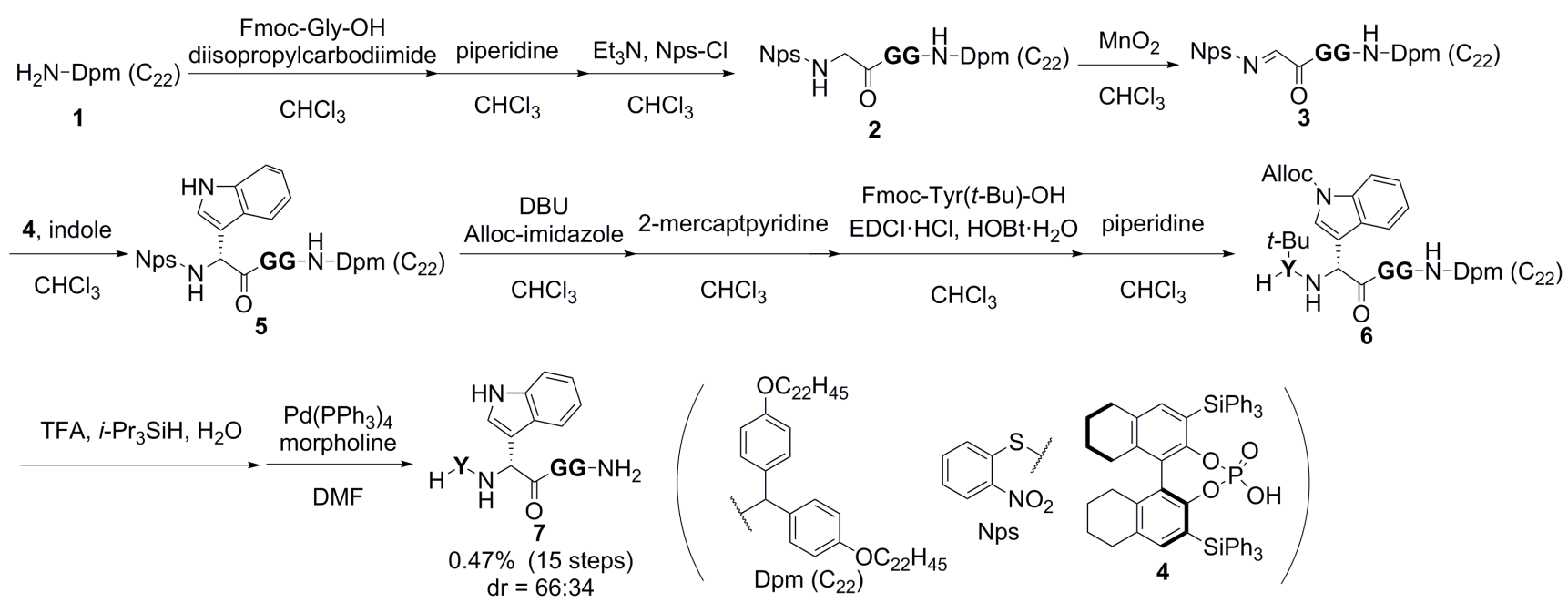

Figure 3: Direct asymmetric Friedel-Crafts reaction to peptidyl imine.

In summary, we developed an unprecedented methodology featuring a direct asymmetric reaction to peptidyl imine. By using this methodology, the preparation of $\alpha$-indolyl glycine-containing peptide was achieved. Optimization of the condition to develop a truly practical methodology for synthesis of unnaturalamino acidcontaining peptide is currently underway.

\section{References}

1. W. Kang, H. Liu, L. Ma, M. Wang, S. Wei, P. Sun, M. Jiang, M. Guo, C. Zhou, J. Dou, Eur. J. Pharm. Sci., 2017, 105, 169.

2. (a) D. Takahashi, T. Yano, T. Fukui, Org. Lett., 2012, 14, 4514. (b) G. Tana, S. Kitada, S. Fujita, Y. Okada, S. Kim, K. Chiba, Chem. Commun., 2010, 46, 8219.

3. T. Inokuma, K. Nishida, A. Shigenaga, K. Yamada, A. Otaka, Heterocycles, 2018, in press. (DOI: 10.3987/COM-18-S(T)86)

4. M. J. Wanner, P. Hauwert, H. E. Schoemaker, R. de Gelder, J. H. van Maarseveen, H. Hiemstra, Eur. J. Org. Chem., 2008, 180.

5. T. Inokuma, T. Jichu, K. Nishida, A. Shigenaga, A. Otaka, Chem. Pharm. Bull., 2017, 65, 573.

6. N. V. Sewgobind, M. J. Wanner, S. Ingemann, R. Gelder, J. H. van Maarseveen, H. Hiemstra, J. Org. Chem., 2008, 73, 6405.

7. S. T. Heller, E. E. Schultz, R. Sarpong, Angew. Chem. Int. Ed., 2012, 51, 8304. 